\title{
Effect of Fruit Location on Apple Detachment with Mechanical Shaking
}

\author{
Long $\mathrm{He}^{1}$, Han $\mathrm{Fu}^{1,3}$, Manoj Karkee1,2, and Qin Zhang ${ }^{1 *}$
}

Abstract: Fresh market apples are picked manually around the world. To reduce dependence on seasonal labour and minimize harvest costs, shake and catch harvesting methods have been investigated (no commercialized product). During shaking, certain amount of fruits could not be detached primarily due to insufficient level of transferred energy. The primary goal of this study was to investigate the efficiency in detaching fruit from different locations of tree branches in modern trellis-trained trees. A fruit location index was formulated and estimated to identify the location of targeted apples on a branch by considering the geometric dimensions of fruit bearing twig (twig index) and excited branch (branch index). A dynamic test system was developed to measure the response of fruit under certain shaking modes. The weights of twig index and branch index were optimized with maximizing $R^{2}$ of regression model between fruit acceleration and fruit location index. This study indicated that the fruit location has a critical influence on fruit detachment with shaking. Test fruits ('Envy' variety) could generally be detached within $5 \mathrm{~s}$ of shaking when fruit acceleration was higher than $5 \mathrm{~g}$, and the corresponding fruit location indices were $0.071,0.06$, and 0.061 in three test frequencies. Harvesting tests showed that over $90 \%$ of fruits with location index greater than 0.06 were detached under $20 \mathrm{~Hz}$ shaking. Fruit quality assessment was not included in this study. The study provided baseline knowledge and information for improving the fruit canopy management practices to obtain high fruit removal efficiency. 
Keywords: fresh market apple, mechanical harvest, shake and catch, fruit detachment, fruit location

\section{Introduction}

Apple is one of the most valuable fruit crops in the USA. The USA farmers grow around 5 million tons of apples on average with the wholesale value of approximately $\$ 4$ billion and predicted additional downstream economic activities totaling roughly $\$ 14$ billion each year (US Apple Association, 2016). Currently, hand picking is the only commercial harvesting method for

fresh market apples, which is labour intensive and costly. What is more, the high demand for seasonal labour and the increasingly uncertain availability of labour pose a significant risk to growers, who may not have sufficient human resources for timely harvesting (Fennimore \& Doohan, 2008; Calvin \& Martin, 2010). The industry needs technological innovations for fresh market fruit harvesting, which will allow fresh market apple growers to remain competitive in the global marketplace. Mechanical harvesting is one of the key methods to address these challenges.

Mass harvesting with a vibration or shaking mechanism is one of the widely investigated methods for mechanical harvesting of tree fruit crops. The basic principle of harvesting with a shaking mechanism is to transmit kinetic energy to fruiting branches, which is used to generate a detaching force on the fruit-stem interface to detach fruit from the tree (Erdoğan, Güner, Dursun, Gezer, 2003). During shaking, trees respond differently to different excitation frequencies and amplitudes, and a fruit could be removed with one or combined motions of pendulum motion, tilting motion, twisting motion, and beam-column motion (Diener, Mohsenin, Jenks, 1965; Cooke \& Rand, 1969). Meanwhile, it was also found that stem fatigue during a repeated bending 
motion played an important role in fruit detachment removal (Rand \& Cooke, 1970). Input vibration energy (shaking frequency and amplitude) and the biophysical characteristics of the tree/fruit system (including tree architecture, branch dimension, fruit variety, etc.) would be the major factors influencing the fruit removal efficiency. In our ongoing work, an average fruit removal efficiency (within the actuation zone) of $85 \%$ was achieved for 'Jazz' apples under shaking frequency of $20 \mathrm{~Hz}$, showing a potential for a shake-and-catch harvesting technique to targeted branch/fruit section trained to trellis wires (Karkee et al., 2016). Input vibrations at higher frequencies result in better fruit removal efficiency, but they are often associated with a greater likelihood of damage to the fruit and tree (Norton et al., 1962). In contrast, lower frequencies may cause a proportion of fruit to remain on the tree due to insufficient detaching force delivered to fruit locations (Diener et al., 1965).

In order to improve the fruit removal efficiency, investigation of the principle of fruit removal for different crops has been reported extensively since 1960s. Some studies focused on the physical properties and vibration characteristics of tree branches (Hussain, Rehkugler, Gunkel, 1975; Castro-García, Blanco-Roldán, Gil-Ribes, Agüera-Vega, 2008; Gupta, Ehsani, Kim, 2015). Others focused on the stem-fruit dynamic response to different vibrations (Parchomchuk \& Cooke, 1972; Crooke \& Rand, 1969; Rand \& Cooke, 1970). Fruit at different locations on a branch could also affect the fruit detachment effectiveness (Diener et al., 1965). In addition, point of attachment of fruit in the different branch/fruit structures, e.g. directly attached, free branch, and hangers, also affects effectiveness of fruit detachment techniques (Diener et al., 1965). Researches also suggested to shorten the long and thin branches (Fridley \& Ching, 1975) 
and to adopt modern trellised systems (Zhou et al., 2016) to improve fruit removal efficiency in mechanical harvesting.

Most reported studies focused on using mathematical models to study the energy/force transmission in tree branches or the detachment mechanism between fruit and stem. There are only a few studies reported on finding a quantitative expression of how the location of a fruit on a branch would affect fruit dynamic response and detaching force under certain vibrations. As fruit trees are increasingly trained towards more uniform and modernized architectures (SNAP: Simple, Narrow, Accessible, and Productive), the ability for mechanical harvesting to achieve high harvesting efficiency with good fruit quality is in reach (De Kleine \& Karkee, 2015; He, Fu, Karkee, Zhang, 2016). It is feasible to investigate the response of individual fruit within a targeted tree branch with modern architectures. The primary goal of this study is to provide guidelines for mechanical harvesting of apples trained in modern fruiting wall orchard by investigating the vibration in energy transmission to the apples at different locations in a branch. The specific objectives of this study are to: 1) Analyze the relationship between the fruit acceleration and fruit location in a tree branch; 2) Validate the effect of fruit location on fruit detachment efficiency using a targeted (branch-level) shake-and-catch harvesting.

\section{Materials and Methods}

\subsection{Fruit Location Index}

Because SNAP tree architectures are being increasingly adopted by tree fruit growers, all research tasks and experiments in this study were conducted in orchards with SNAP fruiting wall canopies in WA, USA (Fig. 1 shows an example of V-trellis fruiting wall architecture). Those trellised apple trees in Washington State are often trained with six to eight primary branches 
trained horizontally to trellis wires, with some twigs grown laterally from those horizontal branches (also called formal training system).

It is essential to understand the natural growth of branches and fruit in those tree canopies and their response to shaking input so that targeted shake-and-catch harvesting system can be optimized to achieve desired level of performance. For the formally trained trees with branches trained to trellis wire, one section of a horizontal branch and fruit in that section could be viewed as the basic unit of the overall tree canopy. Generally, apples either grow on both main branch and on twigs growing out of the main branches. Figure. 2 illustrates a simplified branch structure with an apple located on a twig as an example.

For each individual fruit in a branch, two indices, twig index and branch index, were defined and used to represent its location with respect to the shaking point. The twig index (or index 1 ) represents the ratio of diameter and length of the twig bearing the targeted fruit, and is defined as Eq. 1; branch index (or index 2 ) indicates the ratio of branch diameter at the shaking point and the distance from the shaking point to the junction point of branch and twig bearing the corresponding fruit, and is defined as Eq. 2.

Where, $\mathrm{d}$ (in $\mathrm{mm}$ ) and 1 (in $\mathrm{mm}$ ) are respectively the diameter and the length of the twig bearing the fruit under consideration; D (in $\mathrm{mm}$ ) is the diameter of the branch at the shaking point, $\mathrm{L}$ is the distance (in $\mathrm{mm}$ ) from the twig-branch junction to the shaking point (middle of the branch). In order to represent the overall fruit location and analyse its effect on fruit detachment, a fruit location index was defined as the weighted sum of these two indices (Eq. 3). To identify the 
weight of each index to determine the overall fruit location index, two coefficients, $a$ and $b$ were defined in Eq. 4.

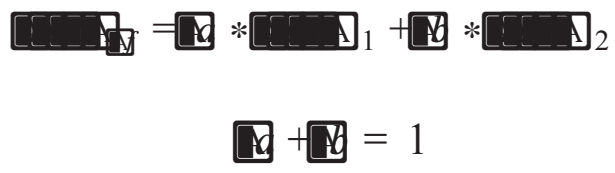

\subsection{Fruit Dynamic Response Test}

To measure the dynamic response of apples with respect to certain input shaking frequencies, an experimental system was developed and a series of field tests was carried out to collect the baseline data need for this study (Fig. 3). The experimental system consisted of an accelerometer (356A26, PCB Piezotronics, Inc., Depew, NY) that was mounted on the branch right next to the shaking point to measure the input excitation acceleration, and another accelerometer (356A16, PCB Piezotronics, Inc., Depew, NY) was mounted on the targeted apple.

All tests were conducted on randomly selected V-trellised 'Envy' apple trees in a commercial orchard (Yakima Valley Orchards, Prosser, Washington) in 2015 harvest season. The trellis system used in the orchard included seven metal trellis wires in both sides of a tree row to form a V-shaped canopy architecture (alternate trees growing in the alternate sides of the V-structure) with the trunk and main branches in each side angled at $70^{\circ}$ to the ground. Trees were planted in a flat terrain with inter-row and intra-row spacing of 4.0 and $1.5 \mathrm{~m}$ respectively. The tree branches were firmly tied to the trellis wire with uniform trellis system, and apples were hanging freely along the branches. Prior to the test, the branch length, branch diameter, twig length and twig diameter were measured. The diameter of tested twigs ( $d$ in Eq. 1) averaged $4.8 \mathrm{~mm}$ ranging from 2.7 to $9.2 \mathrm{~mm}$, the twig length ( $l$ in Eq. 1 ) averaged $116.1 \mathrm{~mm}$ ranging from 25.4 to 279.4 $\mathrm{mm}$, the diameter of branches at the shaking point ( $D$ in Eq. 2) averaged $15.0 \mathrm{~mm}$ ranging from 
11.9 to $23.1 \mathrm{~mm}$, and the distance from shaking point to the twig ( $L$ in Eq. 2) averaged $171.7 \mathrm{~mm}$ ranging from 12.7 to $533.4 \mathrm{~mm}$. There were 8 fruits on average for all test branches ranging from 4 to 12. A mechanical branch shaker (adapted from a commercial electric saw, model: 2720, Milwaukee Electric Tool, Brookfield, WI) used a slide-crank mechanism to convert rotational motion into a $32 \mathrm{~mm}$ linear stroke, was hooked to each test branch in a normal direction. The middle point of branch was selected as shaking point to transmit the energy in both directions of the branch. A foam was placed on the ground to prevent the damage of the sensor, and detached fruit with sensor was dropped onto the foam surface in the test.

In the dynamic test, the shaking frequencies of 15,20 , and $25 \mathrm{~Hz}$ were used to shake the randomly selected branches. Prior to test, the shaker was tuned to the required shaking frequency without engaging to the branch. Dynamics of eighteen to twenty apples located at different location of selected branches were studied under each frequency, and the average weight of these fruits was $209 \mathrm{~g}$. The shaking signal was continuously applied until the targeted fruit was detached or a maximum of $5 \mathrm{~s}$ shaking was reached (based on our try-out test, we found that there were very few fruits being detached after $5 \mathrm{~s}$ ).

Two data acquisition modules (NI CompactDAQ 9234, National Instruments, Austin, TX) were used to record all data generated in the test at $1 \mathrm{kHz}$ in NI SignalExpress (SignalExpress 2015, National Instruments, Austin, TX). All of the acceleration data was filtered using a second order lowpass IIR filter with $100 \mathrm{~Hz}$ of cutoff frequency. In the field dynamic test, accelerations in all three axes were recorded at the shaking point and tested fruits. The overall acceleration of shaking point or tested fruit under all three test frequencies was then calculated using Eq. 5. In this study, we averaged five maximum accelerations from the recorded data (if the fruit was 
detached before five cycles, then the average of maximum acceleration in those cycles was used) as the maximum acceleration of the fruit during shaking.

Where, $A c c_{-} x, A c c_{\_} y$, and $A c c_{\_} z$ are the accelerations in $x, y$, and $z$ axis respectively.

\subsection{Fruit Location vs Fruit Acceleration}

As previously discussed, the ratio of diameter and length of the fruit bearing twig, and the ratio of the branch diameter and distance to twig from the shaking point were two major indices used in defining the fruit location. In reality, the energy transmitted to the fruit may also be affected by other factors, such as fruit size, which was not considered in the study. In order to identify the effect of fruit location on the energy transmission, regression model between acceleration of the fruit under certain shaking mode and location index of the targeted fruit was investigated. Prior to deciding the best fitting regression model, we evaluated different regression methods, such as 'power', 'polynomial', and 'logarithmic' functions. Based on the results, a linear regression model (Eq. 6) was selected to represent the relationship as this model achieved the highest coefficient of determination $\left(R^{2}\right)$ while also being the simplest.

Where, $c$ and $d$ are the y-intercept and slop for the linear regression model between fruit acceleration and fruit location index, is the model-projected fruit acceleration for the corresponding fruit location index.

To find the maximum $R^{2}$ (as shown in Eq. 7) for the linear regression model (Eq. 6), coefficients $a$ and $b$ (Eq. 3) defining the fruit location index were optimized using Eq. 8. Equation 8 was used to optimize the coefficients a and b under the constraint of Eq. 3, so that $R^{2}$ value for the linear 
regression model between fruit acceleration and fruit location index is maximized. The coefficient optimization was conducted in Matlab environment (Matlab R2015a, MathWorks Inc., Natick, MA).

Where, is the optimized fruit location index with coefficients of $a$ and $b$; , are the actual and projected accelerations for $i$ th fruit; is the mean acceleration over all fruit samples for a given shaking frequency.

\subsection{Field Validation with Harvesting Tests}

In order to evaluate the calculated optimized fruit location index with respect to the fruit acceleration/fruit removal, a harvesting test (Fig. 4) was conducted in 2015 harvest season using our previous developed shake and catch harvesting prototype (He, Fu, Sun, Karkee, Zhang, 2016). The harvesting test was also completed with 'Envy' variety trees in Prosser, WA, with the same shaker used in the dynamic test. The harvesting test was repeated for 16 randomly selected branches at the shaking frequency of $20 \mathrm{~Hz}$. Variables defining the fruit location were measured for all the fruits in test branches before shaking. These variables included diameter and length of fruit bearing twig, branch diameter at the shaking point, and distance from shaking point to the junction of branch and fruit bearing twig. This study focused on the effect of fruit location to the fruit detachment or fruit acceleration, the fruit damage was not taken into consideration.

\section{RESULTS AND DISCUSSION}

\subsection{Branch and Fruit Response under Shaking}


Figure 5 shows the dynamic response of the test branches at the shaking point under three shaking frequencies of 15,20 , and $25 \mathrm{~Hz}$. The maximum input acceleration increased with increasing shaking frequency, with the mean maximum acceleration of $6.0,12.3$, and $19.3 \mathrm{~g}$ for three shaking frequencies respectively. As shown in Fig. 5, the input acceleration at the shaking points for each shaking test varied even under the same shaking frequency. In the field test, the frequency of shaker may vary between individual shaking due to the varying load to the shaker exerted by branches with varying diameters/sizes. In addition, the sensor location at the shaking point may vary slightly between individual branches due to biological variability of the branch structure (for example, when there is a twig right next to the shaking point, then the accelerometer may have to be installed next to the twig).

The detachment of a specific fruit from a test branch was generally determined by the energy transferred to the fruit (i.e. fruit acceleration). Figure 6 shows the vibration responses of two example fruits under $20 \mathrm{~Hz}$ shaking input, one was detached (Fig. 6a) and the other one was not (Fig. 6b). The curves shown in Fig. 6 were the integration of accelerations in $x, y$, and $z$ axis (ideally, acceleration at each axis was a sine wave) using Eq. 5. The negative portion of the overall acceleration was also projected to the positive side, which resulted in two positive peaks in one shaking cycle. For the detached fruit, the fruit acceleration jumped to very high level at the very beginning, and reached a much higher level than the acceleration of the branch at the shaking location. After certain cycle of high energy vibration, the fruit was detached. However, for the non-detached fruit, the fruit acceleration was lower and smoother, which was normally much smaller than the input acceleration of the branch at the shaking location. 


\subsection{Fruit Acceleration at Different Fruit Location Index}

Figures 7 to 9 present the relationship (represented by linear regression models with certain $R^{2}$ ) between fruit acceleration and different parameters defining fruit locations. In the following several paragraphs, these relationships for three different shaking frequencies $(15,20$ and $25 \mathrm{~Hz})$ are discussed in details.

\section{Fruit Acceleration vs Twig Index}

If only the twig index (ratio of twig diameter and length) was considered in defining the fruit location (e.g. $a=1$ and $b=0$ in Eq. 3), the relationship between fruit acceleration and fruit location under three shaking frequencies can be illustrated by Fig. 7.

As can be seen in the Fig. 7, fruit accelerations increased with the increasing of twig index under

all three shaking frequencies. The fruit acceleration was very small when the fruit location index was small, which increased dramatically with the increasing twig index, especially in higher shaking frequencies of 20 and $25 \mathrm{~Hz}$. Larger twig index means a larger twig diameter, a short twig or both, which has the potential to improve the efficiency of energy transmission from shaking point to fruit locations, and therefore the result is expected. The $R^{2}$ values of regression model between these two variables were $0.47,0.56$, and 0.52 when only twig index was considered in defining fruit location under three frequencies respectively, which showed a good level of dependence of fruit acceleration on twig index under tested shaking frequencies.

\section{Fruit Acceleration vs Branch Index}


The relationship between fruit acceleration and fruit location under all test shaking frequencies was illustrated in Fig. 8 when only the branch index (ratio of branch diameter at shaking point and distance from shaking point to branch-twig junction) was considered in representing the fruit location (e.g. $a=0$ and $b=1$ in Eq. 3). Larger branch index means a larger branch diameter, a closer distance from fruit bearing twig to the shaking point or both, which has the potential to improve the efficiency of energy transmission from shaking point to fruit locations.

As seen in these plots, the fruit acceleration increased with the increasing branch index under all three shaking frequencies. However, the $R^{2}$ values of the linear regression model were smaller in this case $(0.40,0.20$, and 0.054 with respectively for three frequencies) compared to those when only the twig index was considered. The model was increasingly unreliable (lower $R^{2}$ ) in this case with increasing shaking frequency. The results indicated that the effect on fruit acceleration from the branch index variation would be smaller than that with twig index variation. The $R^{2}$ was relatively larger with the shaking frequency of $15 \mathrm{~Hz}$ compared to those with 20 and $25 \mathrm{~Hz}$. When the shaking frequency was $25 \mathrm{~Hz}$, the $R^{2}$ value was only 0.054 , indicating no potential effect of the branch index on the fruit acceleration.

\section{Fruit Acceleration vs Optimized Fruit Location Index}

As both twig index and branch index have effect on the fruit acceleration even with different weights, the optimized fruit location index (that includes both twig index and branch index) was calculated to maximize the $R^{2}$ of the regression model between fruit acceleration and fruit location index. The optimized relationship between fruit acceleration and fruit location index was illustrated in Fig. 9. 
Similar to Figs. 7 and 8, the fruit acceleration increased with the increasing fruit location index under all three shaking frequencies (Fig. 9). The correlation between fruit acceleration and fruit location index was also found to be stronger for shaking tests at lower frequencies. The $R^{2}$ values for the regression model increased to $0.76,0.67$, and 0.61 with optimized fruit location index for shaking frequency of 15,20 , and $25 \mathrm{~Hz}$, respectively, which was comparatively higher than those when only one index was considered. The weighted coefficients of $a$ and $b$ in fruit location index (Eq. 3) were found to be 0.84 and $0.16 ; 0.92$ and $0.08 ; 0.93$ and 0.07 under three shaking frequencies respectively.

In Fig. 9, the circles over the black dots in all three plots represent the data recorded from detached fruits within $5 \mathrm{~s}$ of shaking whereas those without red circles represent non-detached fruits. As seen from the plots, all the fruits with an acceleration of $5 \mathrm{~g}$ or greater were detached under all test frequencies. Therefore, it was assumed that $5 \mathrm{~g}$ is an optimal acceleration threshold for removing 'Envy' apples. The regression models from Fig. 8 also indicated that the fruit location indices needed to be greater than $0.071,0.06$, and 0.061 to achieve $5 \mathrm{~g}$ of fruit acceleration under 15, 20, and $25 \mathrm{~Hz}$ shaking, respectively.

Test results revealed that the amount of acceleration being transmitted to the fruit is the major factor for fruit detachment in mechanical harvesting. As expected, fruit receiving low excitation energy during the shaking were not detached, in general. The location of where a fruit is growing plays a critical role in the acceleration transmitting efficiency. The fruit location index on a branch created in this study quantitatively represented the effect on fruit detachment under certain vibration. For the test variety (e.g. 'Envy'), a fruit location index greater than 0.06 could 
indicate a measure of the transmitted acceleration to the fruit reached the required threshold value for removing the fruit when shaking at the frequency of $20 \mathrm{~Hz}$. This threshold index may vary for different varieties, which will be explored as we conduct more research in the future across various apple varieties.

In Fig. 9, it can be seen that a few fruits with small location index were detached, and in contrast some fruits with large location index were not detached. Taking deeper look into the measurements for those fruits, we found that majority of those unremoved fruits with large location index were on short twig while far from the shaking point (three out eight fruits were at the tip of branch, and another three were close to the tree trunk). For those removed fruits with small location index, we can see all of them were located very close to the shaking point while with long and thin twigs.

\subsection{Harvesting Test Results}

An overall fruit removal efficiency of $65 \%$ (i.e. $35 \%$ of fruits still remained in the branches) was achieved in the harvesting test. Fruit location index was calculated for all the fruit to analyse the role fruit location index can play in the ability of a shaking mechanism to detach the fruit from branches (Fig. 10). As $20 \mathrm{~Hz}$ of shaking was used, the fruit location index of 0.06 and above would be required to obtain $5 \mathrm{~g}$ acceleration for fruit detachment. Therefore, the evaluation of relationship between fruit location index and fruit detachment in the harvesting test was based on the location index of 0.06 .

About $94 \%$ of fruits with fruit location index larger than 0.06 were detached, and over $90 \%$ of fruits with fruit location index less than 0.06 were not detached. For all of the detached fruits, 
about $80 \%$ of them were with fruit location index greater than 0.06 , which means that roughly $20 \%$ of detached fruits were even with fruit location index less than 0.06 . 'Envy' is generally regarded as tougher variety for fruit detachment with bigger pedicel fruit retention force. About $35 \%$ of the detached fruit included twig or spur with them. A closer observation revealed that some of the fruits with smaller fruit location index were detached with twigs attached to them indicating that longer or thinner twigs might be broken during shaking. The results indicated that training and pruning of tree branches to achieve a certain level of location index will be important to achieve high fruit removal efficiency while minimizing spur or twig removal.

This study quantitatively showed a strong relationship between the effectiveness of a shaking harvester in removing or detaching fruit and location of the fruit growing on a branch. Generally, a fruit with bigger location index (larger diameter or shorter branch or both) implies that the fruit is located at a place where it is easier for kinetic energy to be transmitted and therefore is easier to be detached. The results from the harvesting tests verified the relationship and validated that concept that fruit removal is easier when fruit location index is greater. The fruit damage is not within the scope of this study, while the fruit response (acceleration) under shaking could potentially relate to fruit damage. As shown in Fig. 9, some fruits were removed with much greater acceleration than required value when they had big location indices. Those fruits had high chance to generate strong fruit-to-branch and/or fruit-to-fruit impact, resulting in high chance of fruit damage. In our future study, a varying shaking frequency gradually from low to high will be used to shake the tree branch to remove fruit gently, which has the potential to reduce the mechanical harvesting induced fruit damage. 
Fruit location index proposed in this study could be calculated to predict the possibility of fruit detachment (for example, fruit location index of 0.06 was the threshold for the test variety and tree architecture in this study to be removed under shaking of $20 \mathrm{~Hz}$ and $3.2 \mathrm{~cm}$ stroke). The regression model (Fig. 9) may only work for the particular variety and tree architecture in this study. However, the proposed fruit location index concept could be used for different fruit varieties and tree architectures with different regression models. Of course, shaking location on branch and shaking inputs (shaking frequency and amplitude) may also change the optimal coefficients of $a$ and $b$ in the Eq. 3. Especially, the twig index played dominant role in the overall location index, which could be controlled in the field practically. Therefore, the knowledge and information generated through this study could be used by horticulturists and growers to develop and implement canopy management practices (e.g. tree pruning and training) that can achieve larger location index for most of the fruit, which will potentially lead to higher fruit removal with a mechanical harvesting system.

\section{CONCLUSIONS}

In this study, a fruit location index (normalized representation of how far a fruit is from the shaking location and how large the main branch and secondary twig are) was defined to identify fruit location in a given tree branch. Dynamic response of fruit with respect to its location was analysed under different shaking frequencies, and the relationship between fruit acceleration and fruit location index was analysed. In addition, a set of harvesting tests was completed to evaluate the fruit removal efficiency with varying fruit location index. The major findings from this study could be summarized as follows: 
1. For the fruit variety and tree architecture tested, it was found that the fruit acceleration was strongly related to fruit location represented by the fruit location index. When the location index was larger, the fruit acceleration was generally higher. For example, under $20 \mathrm{~Hz}$ shaking, fruit acceleration could go up to $11.6 \mathrm{~g}\left(\mathrm{~g}=9.8 \mathrm{~m} / \mathrm{s}^{2}\right)$ from $3.4 \mathrm{~g}$ when the location index goes to 0.1 from 0.05 based on the regression model in Fig. 8 b.

2. Comparing to the branch index, twig index played a major role in the overall fruit location index, with the weight coefficients of 0.92 and 0.08 for twig index and branch index respectively when the shaking frequency was $20 \mathrm{~Hz}$ with $32 \mathrm{~mm}$ stroke.

3. Fruit acceleration threshold of $\sim 5 \mathrm{~g}$ was found to be generally sufficient in detaching fruit when 15, 20 and $25 \mathrm{~Hz}$ shaking was used. The corresponding fruit location indices were found to be $0.071,0.060$, and 0.061 to achieve the desired level of fruit acceleration.

4. The harvesting test results indicated that the fruit location index will have a strong relationship with fruit detachment or removal efficiency. During this test, about $90 \%$ of fruits with location index larger than 0.06 were detached when the shaking frequency was $20 \mathrm{~Hz}$ with $32 \mathrm{~mm}$ stroke.

The fruit location index formulated and estimated in this study has a critical influence on fruit detachment, however, other parameters may also affect fruit detachment efficiency. More variables such as fruit size and twig orientation will be included in our future study of fruit detachment evaluation. Meanwhile, more field study will be conducted to evaluate the proposed concept with different varieties and tree architectures. 


\section{ACKNOWLEDGEMENTS}

This research was partially supported in part by United States Department of Agriculture (USDA)'s Hatch and Multistate Project Funds (Accession No 1005756 and 1001246), USDA National Institutes for Food and Agriculture competitive grant (Accession No 1005200), and Washington State University (WSU) Agricultural Research Center (ARC). China Scholarship Council (CSC) sponsored Han Fu conducting collaborative PhD Dissertation research at WSU Center for precision and Automated Agricultural Systems (CPAAS). Any opinions, findings, conclusions, or recommendations expressed in this publication are those of the authors and do not necessarily reflect the view of the U.S. Department of Agriculture and Washington State University.

\section{REFERENCES}

Castro-García, S., Blanco-Roldán, G.L., Gil-Ribes, J.A., \& Agüera-Vega, J. (2008). Dynamic analysis of olive trees in intensive orchards under forced vibration. Trees, 22(6), 795-802.

Cooke, J.R. \& Rand, R.H. (1969). Vibratory fruit harvesting: a linear theory of fruit-stem dynamics. Journal of Agricultural Engineering Research, 14(3), 195-209.

Calvin, L. \& Martin, P. 2010. The U.S. Produce Industry and Labor: Facing the Future in a Global Economy. Washington D.C.: Economic Research Services, USDA. Available at: http:// www.ers.usda.gov/media/135123/err106.pdf. Accessed on: 3/15/2016.

De Kleine, M.E. \& Karkee, M. (2015). A Semi-Automated Harvesting Prototype for Shaking Fruit Treebranchs. Transactions of the ASABE, 58(6), 1461-1470. 
Diener, R.G., Mohsenin, N.N., \& Jenks, B.L. (1965). Vibration characteristics of trellis-trained apple trees with reference to fruit detachment. Transactions of the ASAE, 8(1), 20-24.

Erdoğan, D., Güner, M., Dursun, E., \& Gezer, İ. (2003). Mechanical harvesting of apricots. Biosystems Engineering, 85(1), 19-28.

Fridley, R.B. \& Ching, Y. (1975). Computer analysis of fruit detachment during tree shaking. Transactions of the ASAE, 18(3), 409-415.

Fennimore, S.A. \& D.J. Doohan. (2008). The challenges of specialty crops weed control, future directions. Weed Technology, 22, 364-372.

Gupta, S.K., Ehsani, R., \& Kim, N.H. (2015). Optimization of a Citrus Canopy Shaker Harvesting System: Properties and Modelling of Tree Branches. Transactions of the $A S A B E, 58(4), 971-985$.

He, L., Fu, H., Karkee, M., \& Zhang, Q. (2016). Effect of fruit location on apple detachment with mechanical shaking. IFAC-PapersOnline, 49(16), 293-298.

He, L., Fu, H., Sun, D., Karkee, M., \& Zhang, Q. (2016). A shake and catch harvesting system for 'Jazz' apples trained in vertical fruiting wall architecture. ASABE Paper No. 162461420. ASABE, St. Joseph, Mich.

Hussain, A.A.M., Rehkugler, G.E., \& Gunkel, W.W. (1975). Tree branch response to a periodic discontinuous sinusoidal displacement. Transactions of the ASAE, 18(4), 614-617.

Karkee, M., Q. Zhang, M. Whiting, L. He, H. Fu, \& H. Xia. (2016). Localized shake-and-catch harvesting for fresh market apples. CIGR-AgEng Conference. June 26-29, Aarhus, Denmark. Norton, R.A., Claypool, L.L., Leonard, S.J., Adrian, P.A., Fridley, R.B., \& Charles, F.M. (1962). Mechanical harvest of sweet cherries. California Agriculture, 16(5), 8-10. 
Parchomchuk, P. \& Cooke, J.R. (1972). Vibratory harvesting: an experimental analysis of fruitstem dynamics. Transactions of the ASAE, 15(4), 598-0603.

Rand, R.H. \& Cooke J.R. (1970). Vibratory fruit harvesting: a non-linear theory of fruit-stem dynamics. Journal of Agricultural Engineering Research, 15(4), 356-363.

US Apple Association. 2016. Annual U.S. Apple Crop Stats. Available at: http://usapple.org/ fact/ id-est-non-ducimus-sit-quam-commodi/; Accessed on: 3/20/2016.

Zhou, J., He, L., Whiting, M., Amatya, S., Larbi, P.A., Karee, M., \& Zhang, Q. (2016). Field evaluation of a mechanical-assist cherry harvesting system. Journal of Agricultural Safety and Health, 9(4), 324-331. 


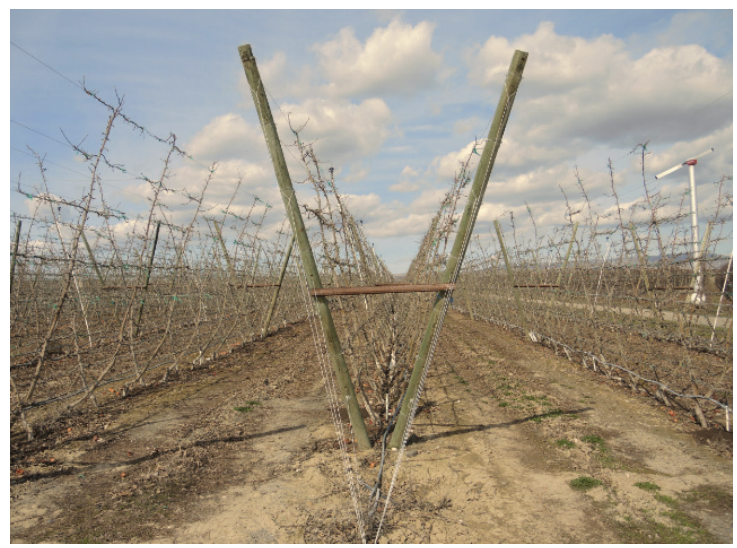

Fig. 1. Apple trees with V-trellis canopy architecture in WA, USA

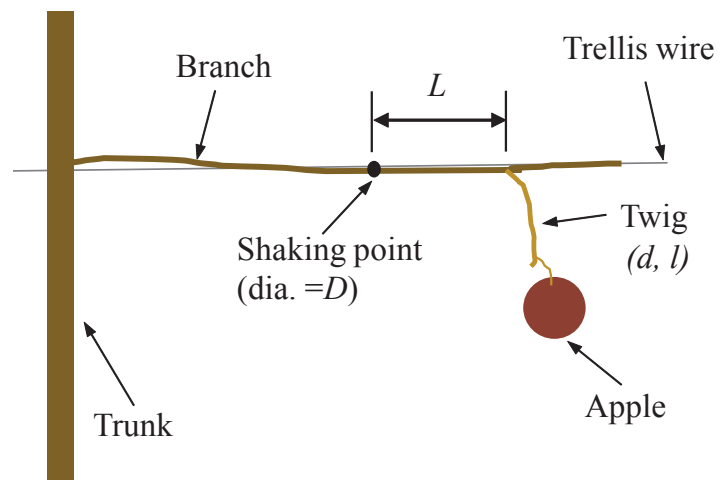

Fig. 2. An illustration of a typical trellis trained branch with fruit located at a twig as an example

a)

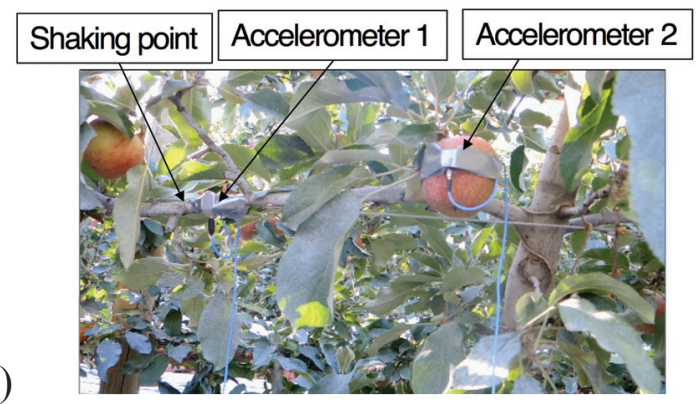

b)

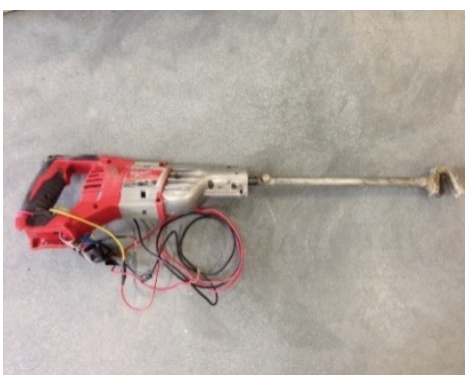

Fig. 3. Illustration of dynamic test setup, a) shaking point and the installed sensors; b) shaker used in the test 


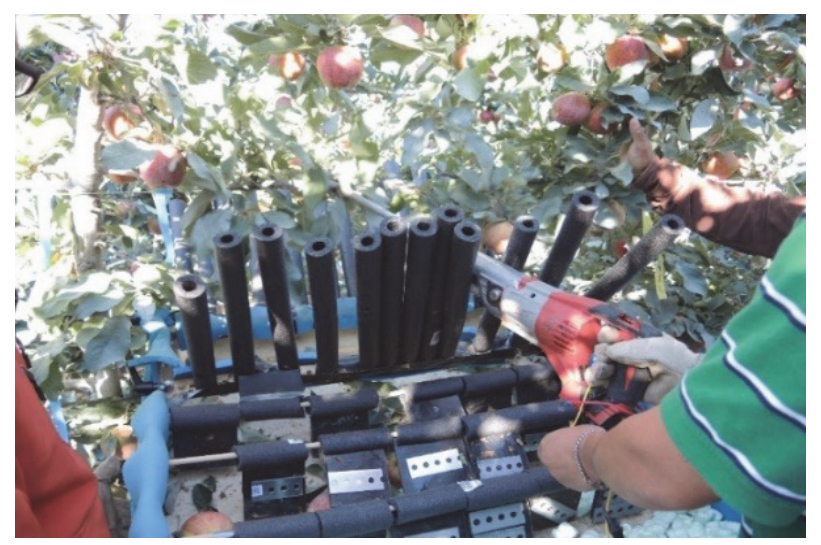

Fig. 4. Harvesting test using the developed shake and catch prototype

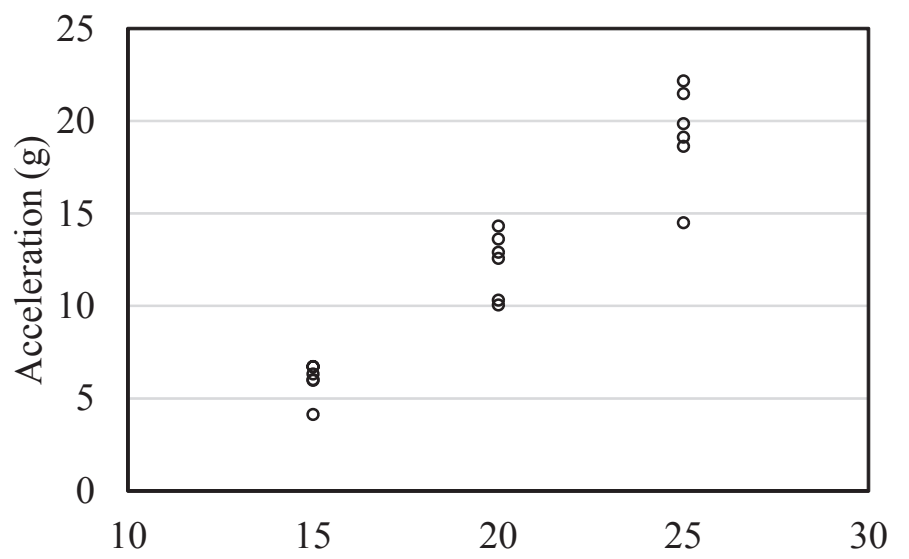

Fig. 5. The maximum acceleration of tree branches at shaking point under different shaking frequencies 


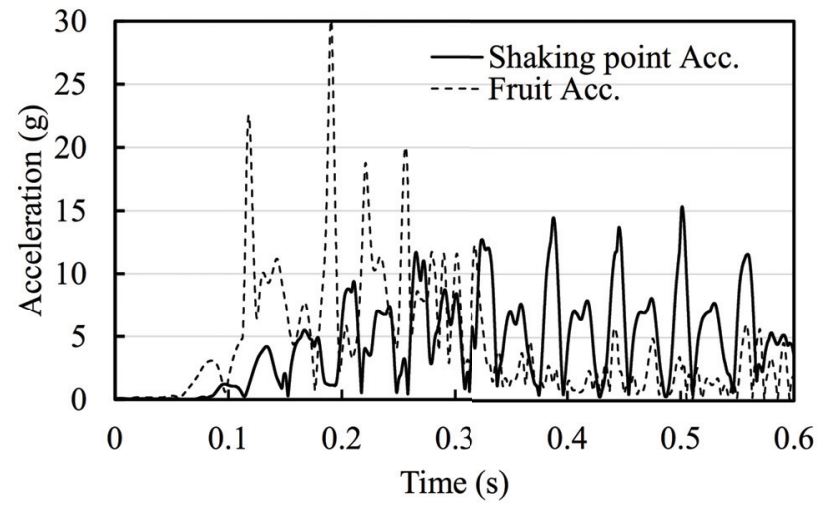

a)

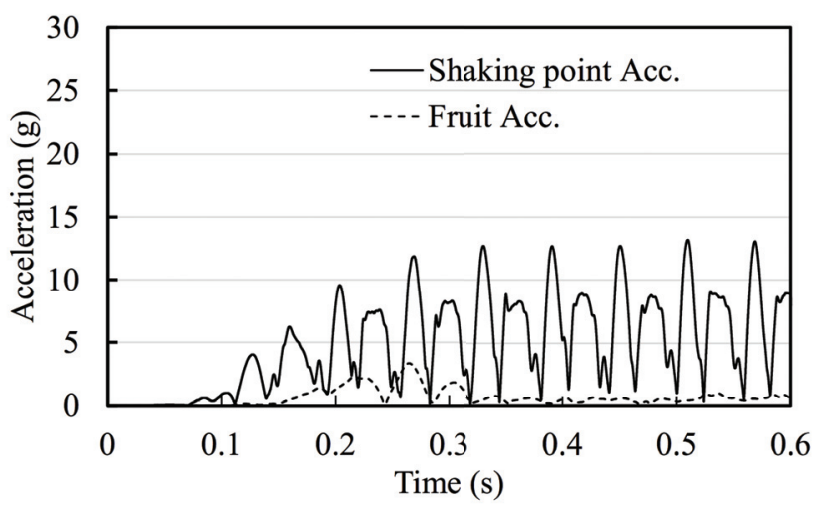

Fig. 6. Examples of accelerations at fruit and shaking point under shaking, a) detached fruit; b) non-detached fruit. 


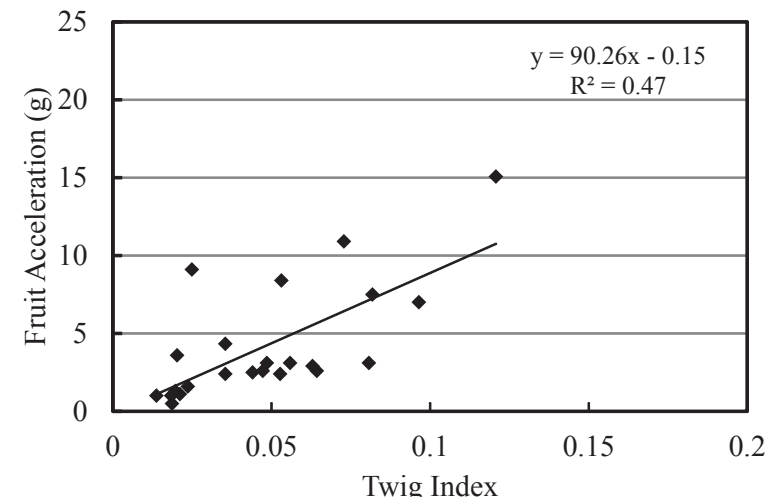

a)

Twig Index

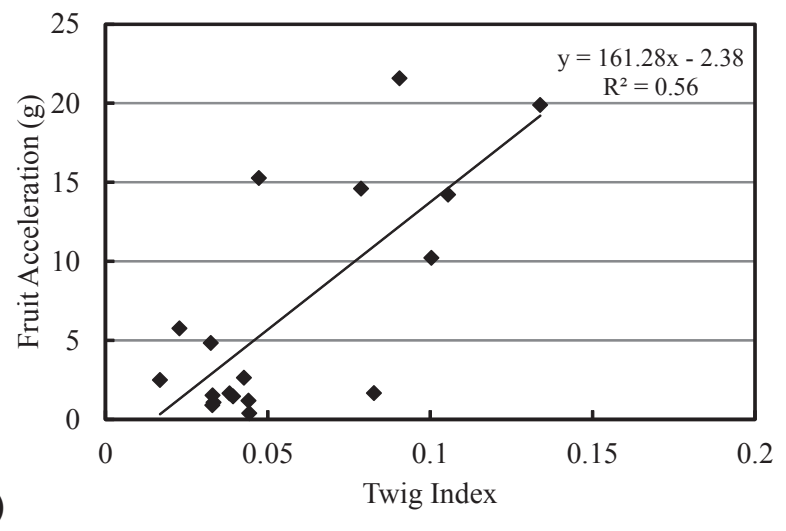

b)

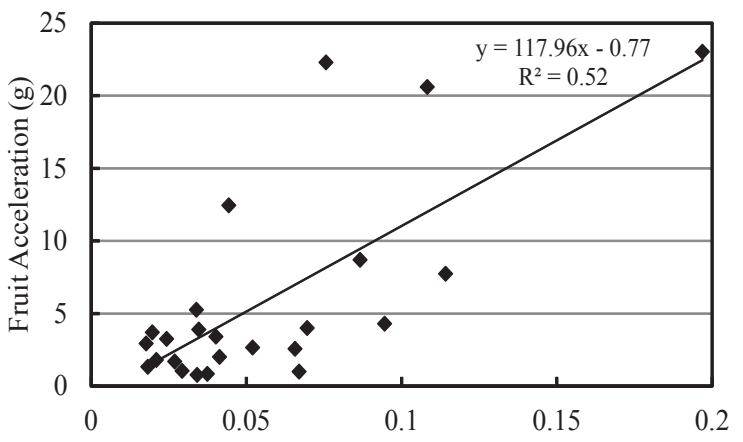

c)

Twig Index 
Fig. 7. The relation between fruit acceleration and the twig index (e.g. $a=1$ and $b=0$ in equation 3). a) $15 \mathrm{~Hz}$ shaking; b) $20 \mathrm{~Hz}$ shaking; and c) $25 \mathrm{~Hz}$ shaking.

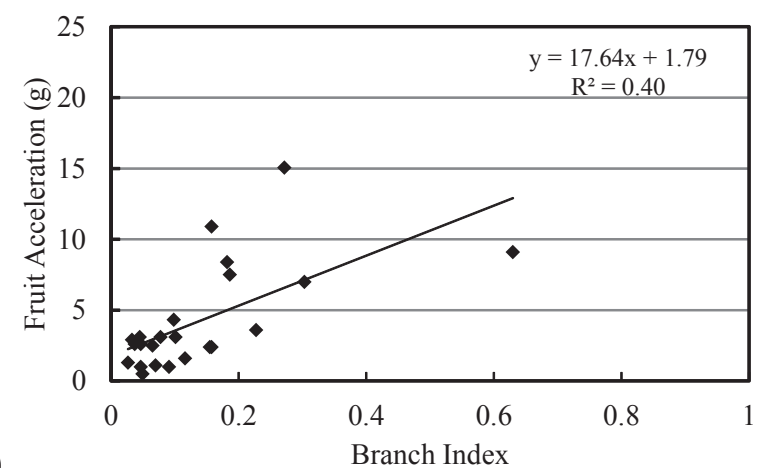

a)

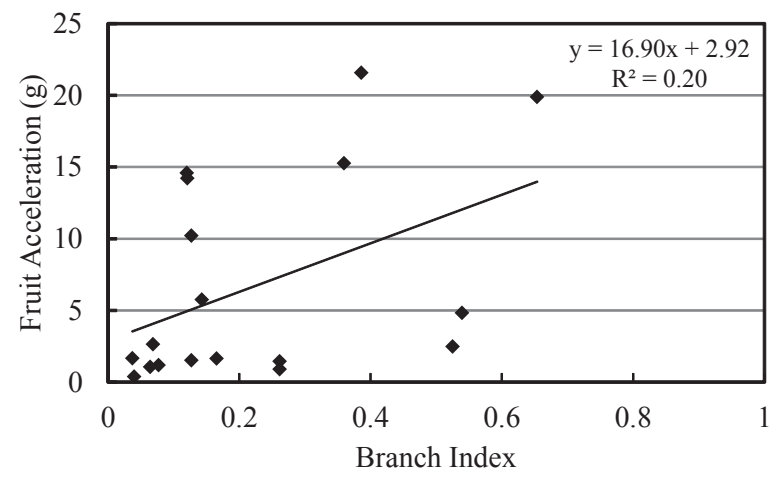

b)

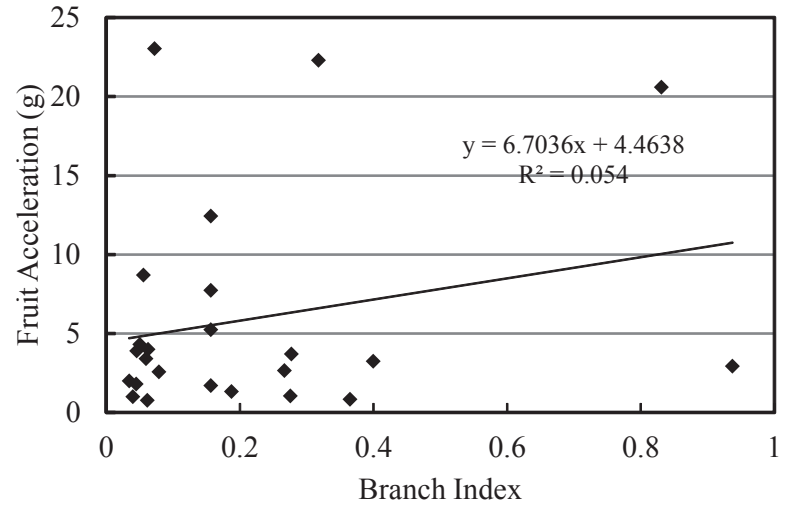

Fig. 8. The relation between fruit acceleration and the branch index (e.g $a=0$ and $b=1$ in equation 3); a) $15 \mathrm{~Hz}$ shaking; b) $20 \mathrm{~Hz}$ shaking; and c) $25 \mathrm{~Hz}$ shaking. 


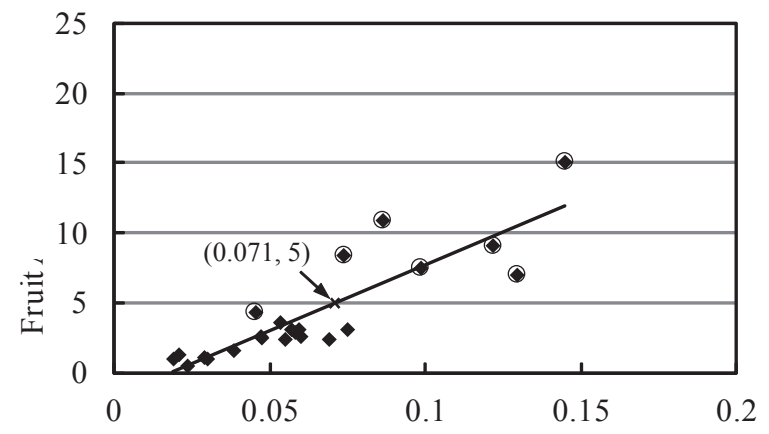

a)

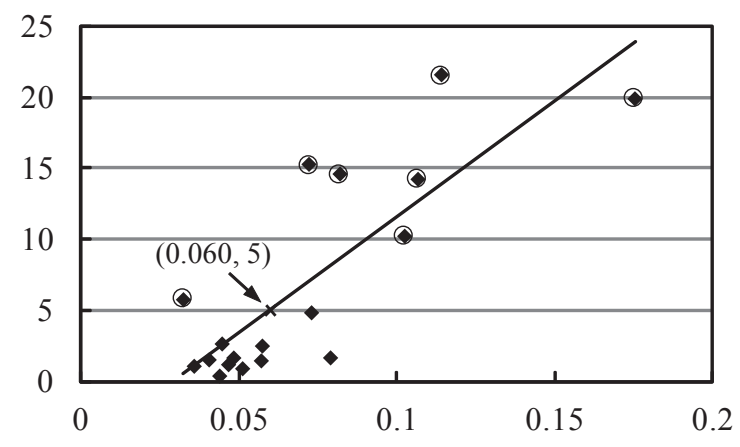

b)

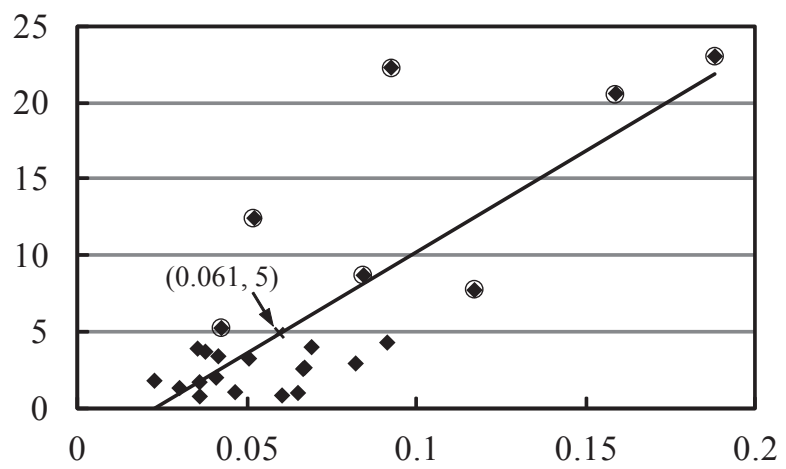

c)

Fig. 9. The correlation between fruit acceleration and fruit location index with considering both twig index and branch index, a) $15 \mathrm{~Hz}$ shaking; b) $20 \mathrm{~Hz}$ shaking; and c) $25 \mathrm{~Hz}$ shaking. The 
circles over the black dots represent the detached fruits. Based on equation 8 , the optimized coefficients $a$ and $b$ in equation 3 are found to be 0.84 and $0.16 ; 0.92$ and $0.08 ; 0.93$ and 0.07 respectively for the shaking frequency of 15,20 , and $25 \mathrm{~Hz}$ respectively).

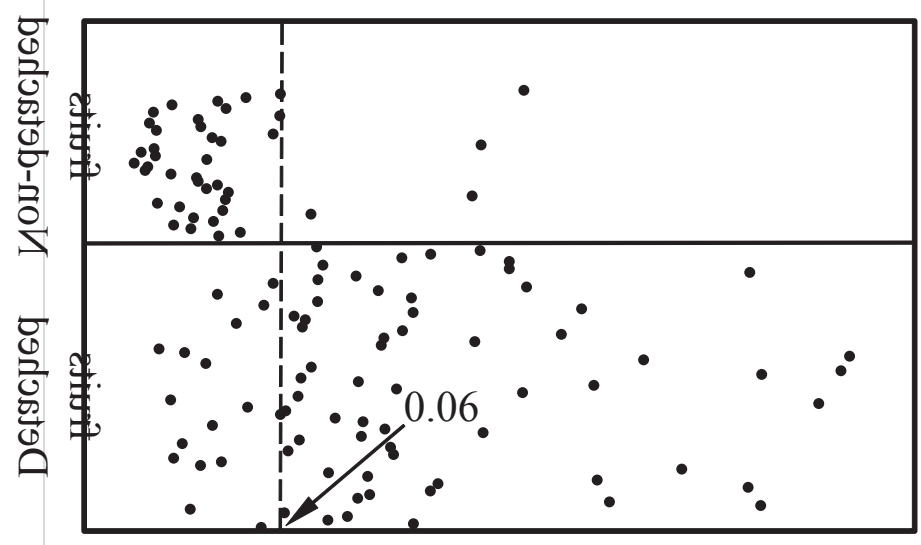

Fig. 10. Distribution of fruit location index for both detached and non-detached fruit samples used in the harvesting test. 